\title{
The dominance-based rough set approach to cylindrical plunge grinding process diagnosis
}

\author{
Pawel Lezanski $^{1}$ - Maria Pilacinska ${ }^{2}$
}

Received: 19 October 2015 / Accepted: 23 May 2016 / Published online: 8 June 2016

(C) The Author(s) 2016. This article is published with open access at Springerlink.com

\begin{abstract}
The dominance-based rough set approach is proposed as a methodology for plunge grinding process diagnosis. The process is analyzed and next its diagnosis is considered as a multi-criteria decision making problem based on the modelling of relationships between different process states and their symptoms using a set of rules induced from measured process data. The development of the diagnostic system is characterized by three phases. Firstly, the process experimental data is prepared in the form of a decision table. Using selected methods of signal processing, each process running is described by 17 process state features (condition attributes) and 5 criteria evaluating process state and results (decision attributes). The semantic correlation between all the attributes is modelled. Next, the phase of condition attributes selection and knowledge extraction are strictly integrated with the phase of the model evaluation using an iterative approach. After each loop of the iterative feature selection procedure the induction of rules is conducted using the VC-DomLEM algorithm. The classification capability of the induced rules is carried out using the leave-one-out method and a set of measures. The classification accuracy of individual models is in the range of $80.77-98.72 \%$. The induced set of rules constitutes a classifier for an assessment of new process run cases.
\end{abstract}

Pawel Lezanski

plezan@p.lodz.pl

Maria Pilacinska

maria.pilacinska@put.poznan.pl

1 Mechanical Engineering Department, Lodz University of Technology, ul. Stefanowskiego 1/15, 90-924 Lodz, Poland

2 Department of Management and Production Engineering, Poznan University of Technology, ul. Piotrowo 3, 60-965 Poznan, Poland
Keywords Cylindrical plunge grinding · Process diagnosis . Signal processing - Dominance-based rough set approach . Semantic correlation $\cdot$ Rule model building

\section{Introduction and related works}

One of the current thematic priorities in the field of production engineering research is to put into practice knowledgebased manufacturing systems which integrate sensing and control technologies, encompassing not only hardware and software, but also people to imitate human being ways of doing and share their knowledge with people (Tönshoff et al. 2002). Such a manufacturing system has to be based on sensors monitoring process variables characterizing the state of the machining process. A successful diagnosis of the process depends to a great extent on reliable and robust sensors. Signals measured by these sensors have to be a subject of different processing techniques to extract signal features potentially correlated with process state. Next a reasoning decision making system has to be applied to select and integrate the selected features for final diagnosis (Teti et al. 2010). Moreover, an ability to represent the knowledge acquired by the system in a human comprehensive form would be its valuable property.

Grinding belongs to one of the most complex machining processes because is influenced by a great number of random factors. One of the most important of them is a random geometry of grains and their distribution on the wheel cutting surface. As a consequence, analytical modelling and interpretation of grinding process results is very unreliable. Therefore empirical, statistical or artificial intelligence methods are the most useful for these purposes. Due to the same reasons, grinding process diagnosis, control and optimiza- 
tion systems have to be developed as the knowledge-based systems which functionalities are described above.

Process diagnosis in grinding systems has been intensively researched for the last twenty five years. The first works were mainly related to process monitoring problems looking for adequate measures of process state description and signal processing methods. A comprehensive survey of these research efforts in the field of grinding is given in Tönshoff et al. (2002). One of the main conclusions following from this study is that there is a lack of a clear recommendation for the best set of features for grinding process monitoring. The most effective feature set always depends on the process type, its conditions and the criteria of its evaluation. It has to be selected from number of features offered with some redundancy by different measuring and data processing units (Teti et al. 2010). Thus a feature selection procedure, generally known as the estimation of intrinsic dimension of data (Grzenda et al. 2012) is required. Moreover, a feature integration method is needed for the process modelling and its classification of state. Most frequently a combination of data exploration methods is used for all of the needed procedures.

Liao (2010) and Liao et al. (2006, 2007, 2008) investigated grinding wheel condition monitoring during surface grinding of ceramic materials with a resin-bonded diamond wheel using only the acoustic emission (AE) signal generated by the process. They applied different methods of the AE signal feature extraction and selection in time and frequency domain as well as different wheel state statistical and artificial intelligence classification techniques. Results of these studies proved that signal feature selection always increases the quality of classification regardless of the method used for the selection procedure and the kind of classifier. The cardinality of the learning vector and the grinding conditions has a significant influence on the classification results. The quality of classification expressed as a percent of right classifications varied from 70 to $100 \%$. The best results (even up to $100 \%$ ) were obtained for higher values of the specific material removal rates using the discrete wavelet decomposition of the AE signal and different methods of cluster analysis based on a distance matrix generated with the aid of the hidden Markov model (Liao et al. 2006).

Liu et al. (2005) applied the AE signal measurement and the wavelet packet analysis for its feature extraction to reveal grinding burn while grinding a work-piece made of Inconel 718 with an electro corundum grinding wheel. They applied the fuzzy clustering analysis for signal feature selection. By means of fuzzy pattern recognition, they identified grinding burn based on distance criteria. They obtained 1 wrong classification for 13 investigated grinding cases.

Li-Ming et al. (2010) investigated grinding wheel wear during curve grinding using a white corundum grinding wheel. They took advantage of the combinational information of the decomposed vibration signal frequency com- ponents based on the wavelet packet decomposition. They concluded that the extracted features can be used in quantization of wheel wear condition and applied in prediction of wear condition.

A broad survey of the AE signal processing methods for grinding burn detection was presented by Wang et al. (2001). Most of the statistics used by the authors for direct detection of grinding burn based on threshold values appeared to be ineffective. The effectiveness of these features considerably increased when they used them as an input vector to the radial neural network. Similar effectiveness was achieved for the network with Wiener auto regression coefficients as the inputs. The application of AE signals to grinding burn and chatter vibration detection is also discussed by Kwak and Song (2001).

An interesting monitoring and controlling system with an intelligent grinding data base for cylindrical grinding process was proposed by Karpuszewski et al. (2000). The data base was used as a module for the initial grinding parameters selection based on utilization of the genetic algorithms for fuzzy rule base optimization. The monitoring system utilized data fusion from $\mathrm{AE}$ and power sensors, so that most of the troubles in the grinding process could be detected and furthermore, the grinding cycle could be automatically optimized. An artificial neural network (ANN) was used for estimation of the wheel life and the work-piece surface roughness. Fuzzy systems were applied to burn detection and optimization of the grinding cycle. The influence of different dressing parameters on the AE signal was investigated and dressing monitoring system was proposed. A graphical user interface for the whole system was developed. Unfortunately, the applicability of the system cannot be recognized because the authors did not show any verification of the presented results.

A hybrid system for grinding wheel condition monitoring during external cylindrical grinding was presented by Lezanski (2001). The system utilized data and their different processing methods from $\mathrm{AE}$, vibration and grinding force components signals. A feed forward ANN with the sigmoid functions was used for signal feature selection procedure using the weight pruning method and a neuro-fuzzy system for wheel condition estimation. The best performance index of the system reached $83.3 \%$. The ANN could also be used for wheel condition modelling and estimation. A genetic algorithms with fuzzy approach for prediction of grinding power and surface finish was proposed by Nandi et al. (2004).

The discussed works indicate that different methods for the process model building and the process state classification can be applied to achieve the goals of knowledge-based grinding systems. Generally, the choice of a method for the process model building and for the process state classification results from the nature of process features (Brinksmeier et al. 2006). 


\section{A new approach to the grinding process diagnosis}

\section{Restrictions in plunge grinding operations}

The grinding process is considered to be an operation in which the required quality parameters of the work-piece can be achieved with possibly high material removal rates. However the choice of the grinding parameters securing such a goal of the process is subject to many restrictions resulting from opposing effects of machine settings adjustment. For cylindrical grinding operations, these restrictions can be graphically depicted in a very efficient way using the twodimensional diagram of the specific material removal rate $Q_{w}^{\prime}$ as a function of the work speed $v_{w}$ (Maris et al. 1975). It is presented in Fig. 1.

The acceptable working area is delimited by a dynamic stability boundary for small values of $Q_{w}^{\prime}$ and by a burn and other thermal damage constraint for higher values of $Q_{w}^{\prime}$. Additionally this area is narrowed down by restrictions resulting from the required surface roughness (the $R_{a}$ parameter), the allowable normal force $F_{n}$ and the allowable work speed $v_{w}$. However the constraints of the acceptable working area change their locations during the single wheel life period because of the continuous change of the wheel cutting ability and other process disturbances. Under such circumstances, the problem of grinding process diagnosis should be based on the monitoring of the grinding wheel wear and all phenomena related to the process restrictions and can be considered as a multi-criteria decision making problem.

The process state assessment in the case of any machining operation including grinding is made using discrete values expressed as numbers or symbols belonging to a prede-

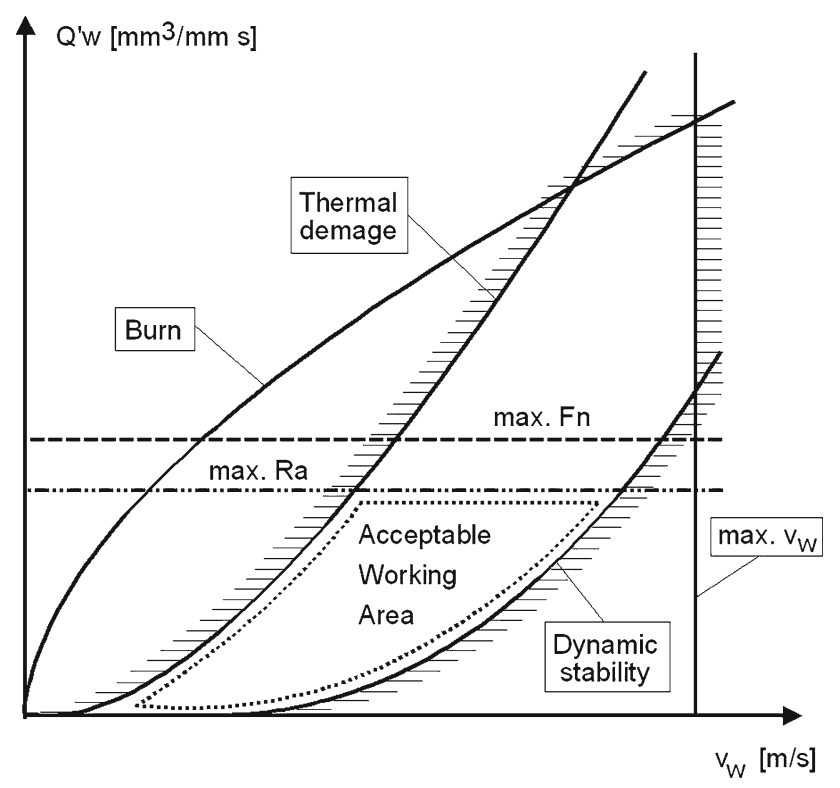

Fig. 1 The acceptable working area for cylindrical plunge grinding fined set e.g. $\{1,2,3\}$ or $\{$ good, bad $\}$. Because of this, the multi-criteria decision making problem in the automatic supervision of the grinding process is reduced to a classification problem of process state and results into predefined classes. It is then possible to include the knowledge of an expert into the assessment procedure through the creation of his/her preferences with regard to the assessment of individual process states. Moreover, if decisions on attributing process state to a specific class are made on the basis of rules which explicitly describe the dependency of the individual states on their symptom values, then the diagnosis of the reasons for this state is possible.

The mentioned conditions can be fulfilled by a novel method based on the modelling of relationships between process individual states and their symptoms using a set of rules which are induced from measured process data. This new method was developed by Greco et al. (2001) and is called the dominance-based rough set approach (DRSA). The DRSA is an extension of the Rough Sets Theory (RST) introduced by Pawlak (1982). The DRSA based models tolerate data inconsistency and ambiguity as well as the artificial neural network models but they are not "black box" type models. Unlike fuzzy logic, the DRSA does not require a discretization of the data and any previous assumptions about the data e.g. about their fuzziness distribution, but, like fuzzy systems, a data analysis with the aid of the DRSA does provide a search for hidden data features and decision making algorithms with the effective tools. Thus, the DRSA, at least partly, eliminates the drawbacks of ANNs and fuzzy systems while preserving their advantages. The DRSA can be used for feature clustering and selection, data selection, detection of nondeterministic relationships, as well as the optimization of decision making processes related to the supervised object. Although there are already studies on applications of the conventional RST to manufacturing (Kusiak 2001; Mannar and Ceglarek 2004; Mannar et al. 2006), for the time being, the DRSA has been proposed for manufacturing process diagnosis only by Pilacinska et al. (2011). The basic concepts of the DRSA are described below [for a complete presentation see Greco et al. (2000), Greco et al. (2001), Greco et al. (2002), Greco et al. (2005), Slowinski et al. (2009)].

\section{Fundamentals of the DRSA}

In the classical RST the indiscernibility relation is used to compare objects described by certain attributes. This relation is the basis for the construction of a rough set representing a concept called a decision class (e.g. a class of a product quality) by discriminating its lower and upper approximations. The objects which belong without any ambiguity to the considered decision class constitute its lower approximation, while all the objects whose membership to the class cannot 
be excluded constitute its upper approximation. Hence, the RST is the tool which enables an analysis of inconsistent and ambiguous data like data possible to be logged during any machining process.

The original rough set idea is failing, however, when preference-orders of attribute domains are to be taken into account what is a very natural concept applied to a multi-criteria comparison of objects. To eliminate this disadvantage, the indiscernibility relation was substituted by a dominance relation and this is the main difference between the DRSA and the classical RST. Use of the dominance relation allows the DRSA to model the preference orders of attribute domains (a kind of domain knowledge) and semantic correlation existing between attributes. The semantic correlation between condition and decision attributes means that improving the value of the condition attribute should not cause a worsening in the value of the decision attribute, if the values of the remaining condition attributes stay unchanged. In other words, an object $x$ dominating object $y$ on all considered ordinal attributes (i.e. $x$ having evaluations at least as high (good) as $y$ on all considered attributes) should also dominate $y$ on the decision (i.e. $x$ should be assigned to at least as high (good) a decision class as $y$ ). This principle is called the dominance principle (or Pareto principle).

The DRSA, as the method of multi-criteria decision analysis uses also the term criteria rather than attributes. A regular attribute has no preference-ordered domain, whereas a criterion (ordered attribute) is an attribute with preferenceordered domain.

A condition criterion may be semantically correlated with a decision criterion. Their relationship can be positive (the greater the better) or negative (the greater the worse). The positive correlation between condition and decision criteria means an occurrence of an increasing (gain type) preference whilst the negative one means an occurrence of a decreasing (cost type) preference.

Violation of the dominance principle leads to inconsistency with respect to dominance relations included in the data consisted of objects representing operation of the investigated system (Blaszczynski et al. 2012). The DRSA is able to handle inconsistencies following from violation of the dominance principle by separation of certain knowledge from the uncertain one. This is why, the DRSA is suited for problems of multi-criteria classification, where classes are ordered and condition attributes are, in general, criteria.

The first step in the framework of the DRSA is the preparation of the data consisted of objects representing operation of the investigated system. For algorithmic reasons, data about objects (classification examples) is represented in the form of a decision table. Each table row represents an object whereas a column represents an attribute (object feature). Each cell in the table is an attribute value (quantitative or qualitative) describing an object.
Formally, a decision table is the 4-tuple $S=<U, Q, V$, $f>$ where $U$ is a finite set of objects (universe), $Q$ is a finite set of attributes, $V=\bigcup_{q \in Q} V_{q}$ and $V_{q}$ is the set of the attribute value $q$, and $f: U \times Q \rightarrow V$ is a total function such that $f(x, q) \in V_{q}$ for every $q \in Q, x \in U$, called an information function. The set $Q$ is, in general, divided into set $C$ of condition attributes and set $D$ of decision attributes. The $D$-elementary sets are called decision classes.

All objects consistent with respect to dominance principle are called correctly classified objects. The ratio of the cardinality of all correctly classified objects to the cardinality of all the objects in the decision table $(U)$ is called the quality of classification approximation.

However some condition attributes in the decision table can be redundant. A reduct is hence defined as a minimal subset of all condition attributes required to keep the quality of classification unchanged. Any decision table can have many reducts. The intersection of all the reducts is known as a core (Greco et al. 2001, 2002).

Induction of decision rules is a complex problem and many algorithms have been introduced to solve it. In order to induct decision rules consistent with a dominance principle specific algorithms have been proposed (Blaszczynski et al. 2011; Greco et al. 2005). One of them called VC-DomLEM algorithm is based on sequential covering. This algorithm can be used, in general, for both ordered and non-ordered data and in the case of non-ordered data, it employs indiscernibility relation. The VC-DomLEM generates a minimal set of decision rules and shows a high predictive capability (Blaszczynski et al. 2011). These rules are called monotonic for their syntax of the form:

If evaluation of object $x$ is greater (or smaller) than given values of some condition attributes, then $x$ belongs to at least (at most) given class.

The above syntax takes into account that condition and decision attributes are ordinal and monotonically related (semantically correlated) (Blaszczynski et al. 2012).

Decision rules extracted from data are considered to be a data model. Thus, in the case of classification problems they do not only describe the data, but they also can be used for prediction.

Classification of new objects by the induced decision rules is the next step of the rough set approach. In this step, recommendations of decision rules for classified objects are aggregated using classification strategies (Blaszczynski et al. 2011). So far two classification methods dedicated for the DRSA were introduced. So-called standard classification method has been presented in Greco et al. (2002). This method is based on the principle that an object covered by a set or rules is assigned to a class resulting from intersection of unions of decision classes suggested by the rules. A new classification method was proposed in Blaszczynski et al. 


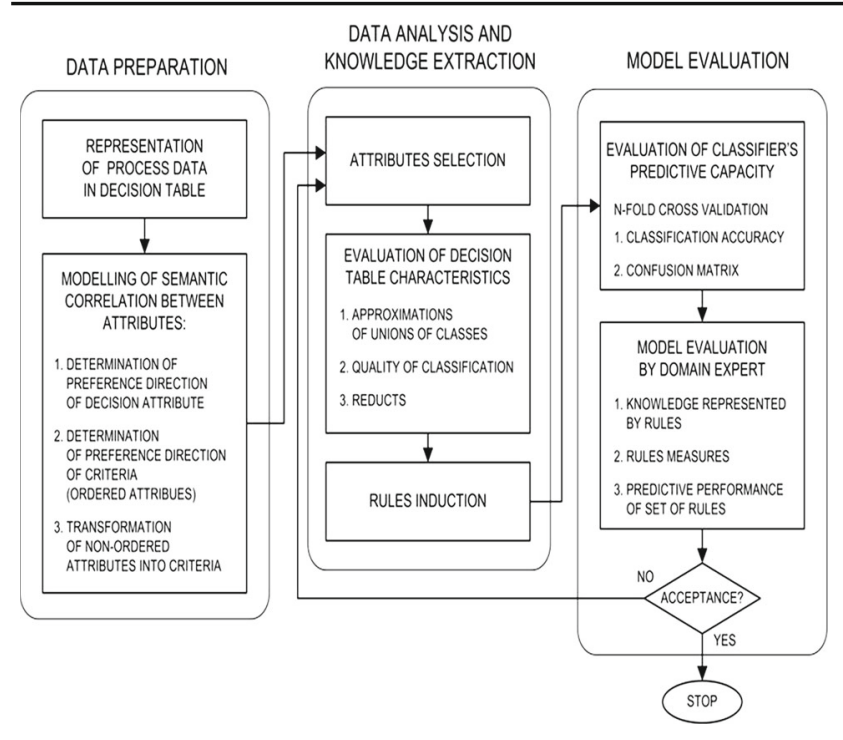

Fig. 2 The DRSA based framework of grinding process diagnosis

(2007). It is based on a notion of a class score coefficient associated with a set of rules covering the classified object. The object is assigned to a class getting the highest score (Blaszczynski et al. 2007, 2012).

\section{Conception of process diagnosis using the DRSA}

In the presented application, the set of rules induced from the experimental data creates a model of a grinding process which can be used for an explanation of patterns hidden in the data and, following this, a classification of new process run cases. The main stages of the process diagnosis conception based on such a methodology are presented in Fig. 2.

The applied procedure consists of three main steps:

- preparation of process data according to DRSA requirements,

- proper data analysis and knowledge extraction,

- evaluation of induced set of rules.

The data analysis and knowledge extraction as well as model evaluation stages are connected by a feedback loop. During the procedure of process model building, these steps are iteratively repeated until the model (set of rules) with a satisfied performance will be found. The all steps of the DRSA based framework are described in the following sections.

\section{Grinding data preparation}

\section{Grinding tests}

The grinding tests were carried out on the modified JOTES SWF-25 external cylindrical grinding machine equipped with adequate control and measurement units (Lajmert and Lezanski 2013). The work-pieces made of 38HMJ steel hardened to $50 \mathrm{HRC}$ were ground using 38A80KVBE electro corundum grinding wheel. The range of grinding parameters applied during the tests exceeded the acceptable working area so that the diagnosis of phenomena being the process limitations would be possible. To achieve this purpose the specific material removal rate $Q_{w}^{\prime}$ equal to 1,2 and $3 \mathrm{~mm}^{3} / \mathrm{mms}$, the ratio $q$ of the wheel peripheral speed $v_{s}$ to the work-piece peripheral speed $v_{w}$ equal to 60,100 and 400 and the wheel speed equal to $40 \mathrm{~m} / \mathrm{s}$ were used. The tests were carried out in series which comprised a number of grinding cycles completed for a single wheel life period with the following eight combination of $Q_{w}^{\prime}$ and $q: Q_{w}^{\prime} 1 q 60, Q_{w}^{\prime} 1 q 100, Q_{w}^{\prime} 1 q 400, Q_{w}^{\prime} 2 q 60, Q_{w}^{\prime} 2 q 100$, $Q_{w}^{\prime} 2 q 400, Q_{w}^{\prime} 3 q 60, Q_{w}^{\prime} 3 q 100$. The $Q_{w}^{\prime} 3 q 400$ appeared to be unfeasible because of an excessively high grinding force and immediate appearance of burn on the ground surface.

The single grinding cycle consisted of $150 \mu \mathrm{m}$ grinding infeed (what corresponds to $100 \mathrm{~mm}^{3} / \mathrm{mm}$ of the specific material removal $\mathrm{V}_{w}^{\prime}$ ) and a rapid wheel retraction. Depending on the applied parameter combination, the single wheel life period consisted of the 8-12 grinding cycles.

The cutting force components, vibration as well as the raw and rout mean square (RMS) value of the acoustic emission signals were recorded during grinding. The difference in pressures inside the pockets of the grinding wheel spindle hydrostatic bearings was utilized for the measurement of grinding forces. The vibration signal was measured by the 4370 Brüel and Kjær piezoelectric sensor and the 3000R Gap Dittel wireless AE sensor were applied for the measurement of the raw and, after an analogue RMS circuit processing, the RMS value of the AE signal.

The profile (micro-geometry) and waviness (macrogeometry) of the grinding wheel cutting surface (WCS) were measured along the wheel circumference. The WCS profile was measured with the aid of a specially designed sensor based on the Carl Zeiss Jena ME10 roughness measuring head. A modified linear variable displacement transducer was used for the WCS waviness measurement (Lajmert and Lezanski 2013). The work-piece roughness was measured as well. These measurements allowed the process state to be reliably correlated with the process variables monitored during grinding.

Special software was written for the grinding machine control as well as for measured data recording using Borland and Visual C++ programming environment (Lajmert and Lezanski 2013). Spectral and statistical analysis of the signals ware made with the aid of the STATISTICA and a software package called the DAQSYSTEM developed in LabVIEW environment. 


\section{Signal feature extraction}

The signal feature extraction and quality assessment of their usefulness for cylindrical plunge grinding diagnosis was preceded by a comprehensive literature study and theoretical analysis of the cylindrical grinding process in the aspect of automatic supervision application (Lajmert and Lezanski 2013). Next, based on this analysis and on the accomplished measurements, methods of signal processing allowing the determination of a set of features correlated with the process state and results were searched for. The results of measurements of quantities directly characterizing the process results like parameters of the grinding WCS profile as well as the work-piece roughness and the state of its thermal damages were used for this purpose. As a result, the determination and verification of the relationships between those two groups of quantities and a qualitative assessment of the determined features usefulness for process supervision were possible. The quantitative assessment of the selected features and their final selection was integrated with the iterative procedure of knowledge extraction and obtained models evaluation.

\section{Direct measures of wheel state and work-piece quality}

The WCS micro-geometry has a significant meaning for the wheel cutting ability. The measurements of the grinding WCS micro-geometry were performed perpendicularly to its envelope in the parallel direction to the grinding speed vector along one trace on the wheel width. The measurements were repeated three times along the measuring length, equal to at least $25 \mathrm{~mm}$ with the radial resolution of $1 / 15 \mu \mathrm{m}$ and the peripheral resolution of $0.01 \mathrm{~mm}$. Thus each single measurement consisted of at least 2500 measuring samples. The Abbott's bearing ratio curve (BRC) and its special parameters (PN EN ISO 13565-2:1999) were used to describe the grinding wheel micro-geometry (Brinksmeier and Werner 1992; Lajmert and Lezanski 2013). The BRC, determined along an assumed measuring length, is replaced by a linear description which divides the whole height of the measured profile into the three characteristic quantities: the core roughness depth $R_{k}$, the reduced peak height $R_{p k}$ and the reduced valley depth $R_{v k}$. The reduced profile height $R_{G e s}$ is equal to the sum of all the three parameters. The method of setting the BRC parameters is illustrated in Fig. 3.

The results of $R_{p k}$ and $R_{G e s}$ measurements are shown in Fig. 4.

The measurements of the WCS BRC parameters revealed that it is not their absolute values but the trend of their changes which allows the assessment of the WCS micro-geometry state to be better recognized.

The development of grinding WCS waviness is strictly related to the development of chatter and in most cases of the

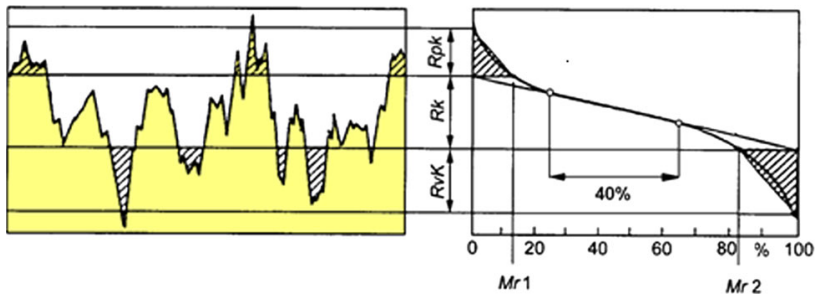

Fig. 3 Parameters of bearing ratio curve (PN EN ISO 13565-2:1999)

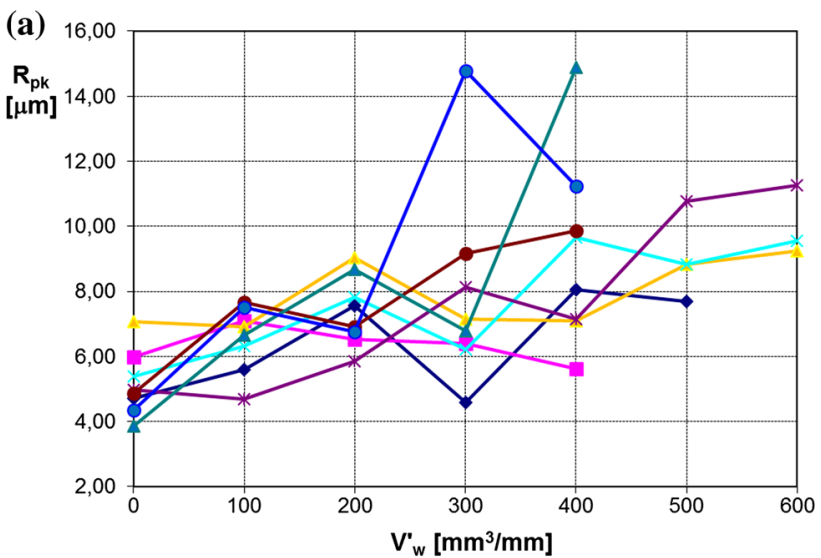

(b)

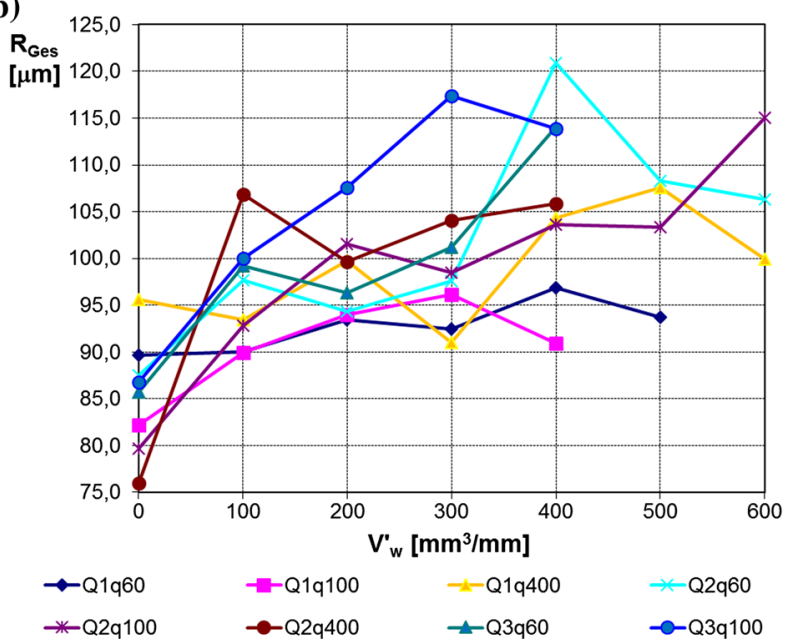

Fig. 4 The $R_{p k}$ (a) and $R_{g e s}(\mathbf{b})$ parameters as a function of the specific material removal for $Q_{w}^{\prime}=2 \mathrm{~mm}^{3} / \mathrm{mms}$

cylindrical grinding is decisive for the grinding wheel life period (Inasaki et al. 2001).

The measurements of the WCS waviness were performed in the same manner as its micro-geometry measurements, but along the whole circumference of the wheel and thus ensuring the values of at least 7500 samples every $0.2 \mathrm{~mm}$. A spectral analysis of the measurements allows an assessment of waviness and out-of-roundness of the wheel to be performed. The harmonic components appearing in the measured profiles correspond to different frequencies of waves on the wheel circumference. The highest amplitudes appeared in 


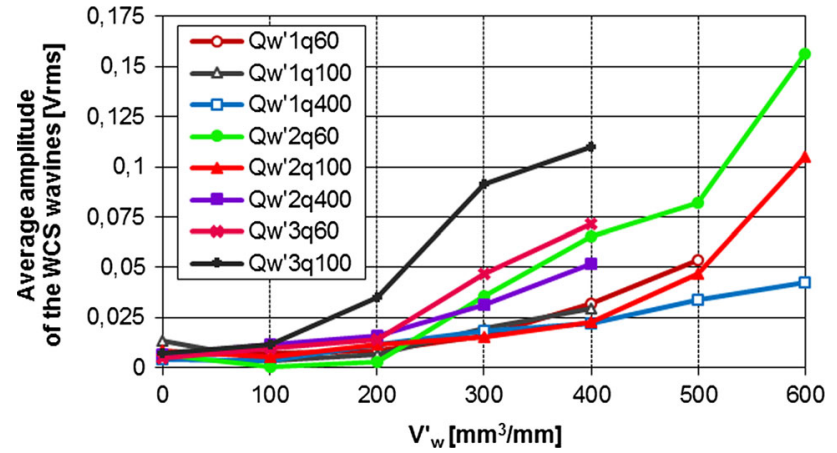

Fig. 5 Wheel average waviness in the range of 10-50 waves per wheel circumference as a function of the specific material removal

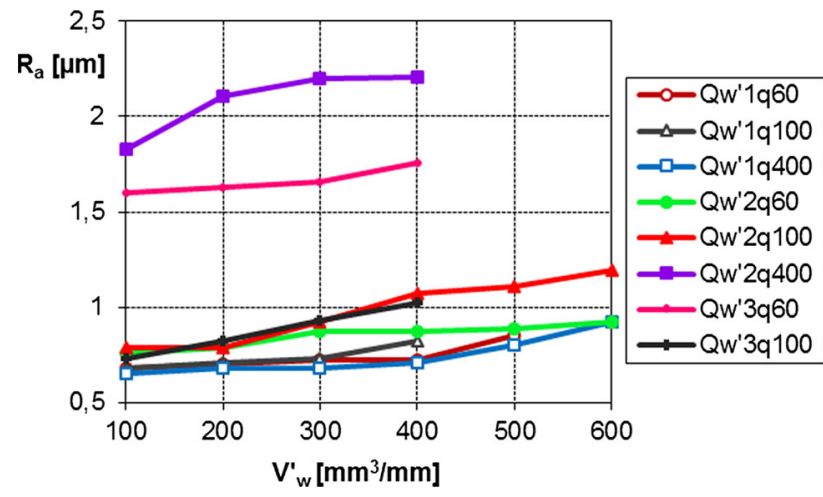

Fig. 6 Work-piece roughness as a function of the specific material removal

the range of 10-50 waves per wheel circumference (Fig. 5). Thus, the average amplitude of the digital Fourier transform (DFT) power spectrum of the wheel circumference profile in this range was used as a measure of the WCS waviness.

The DFT analysis shows that the WCS waviness, being a result of the chatter regenerative effect on the wheel, is a good indicator of the WCS macro-geometry.

The measurements of the work-piece surface roughness was performed for a direct assessment of the work-piece quality after grinding. The results are presented in Fig. 6.

The roughness measurements show that, in all cases, the grinding wheel wear causes an increase of roughness of up to $40 \%$. Moreover, much higher values of roughness have been recorded for the tests performed with the extreme values of the depth of cut $a_{e}\left(a_{e}=\mathrm{Q}_{\mathrm{w}}^{\prime} / \mathrm{v}_{\mathrm{w}}=20 \mu \mathrm{m}\right.$ for the $\mathrm{Q}_{\mathrm{w}}^{\prime} 2 \mathrm{q} 400$ tests) and the work-piece speed $v_{w}\left(v_{w}=0.67 \mathrm{~m} / \mathrm{s}\right.$ for the $\mathrm{Q}_{\mathrm{w}}^{\prime} 2 \mathrm{q} 400$ tests). Such results support proven in numerous investigations a detrimental effect of increase of the depth of cut and the work-piece speed on the surface roughness. The work-piece surface roughness in all the other test cases was smaller because an increase in $a_{e}$ was compensated by decrease in $v_{w}$ and vice versa (see Fig. 1).

\section{Feature extraction from the measured process variables}

Mechanical vibration and the root mean squared value of the EA signal were recognized as useful process quantities for the grinding wheel macro-geometry supervision.

As it was said before the development of grinding WCS waviness is strictly related to the development of chatter thus it can be supervised with the aid of a spectral analysis of the vibration generated during grinding. The vibration signal generated during cylindrical grinding can be considered as linear and stationary so it can be analyzed with the aid of DFT.

The changes of the DFT power spectrum average value of vibration signals during the wheel life period in the frequency ranges of $600-1000$ and $1200-2000 \mathrm{~Hz}$ for the all grinding tests were discovered and they are presented in Fig. 7.

Based on the performed frequency-amplitude characteristics of the mechanical system elements, it was established that these are frequency ranges which contain the harmonics

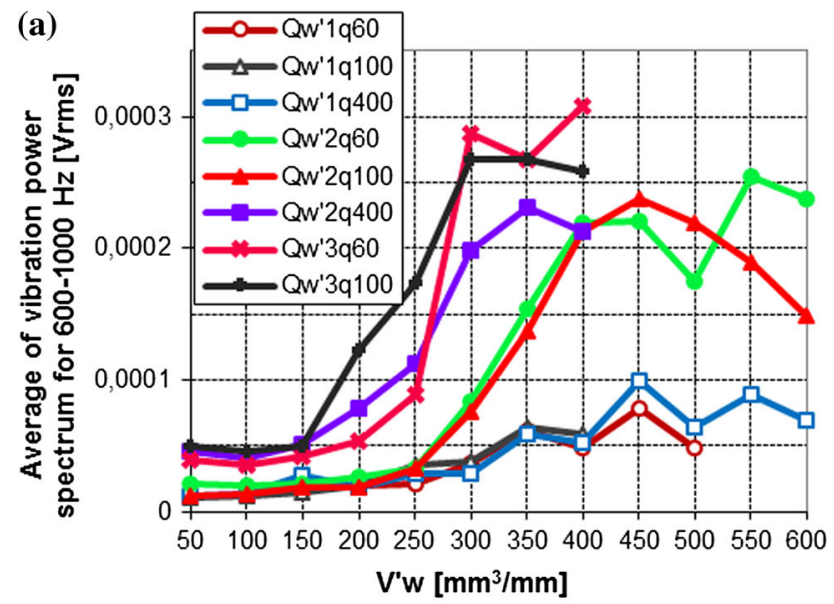

(b)

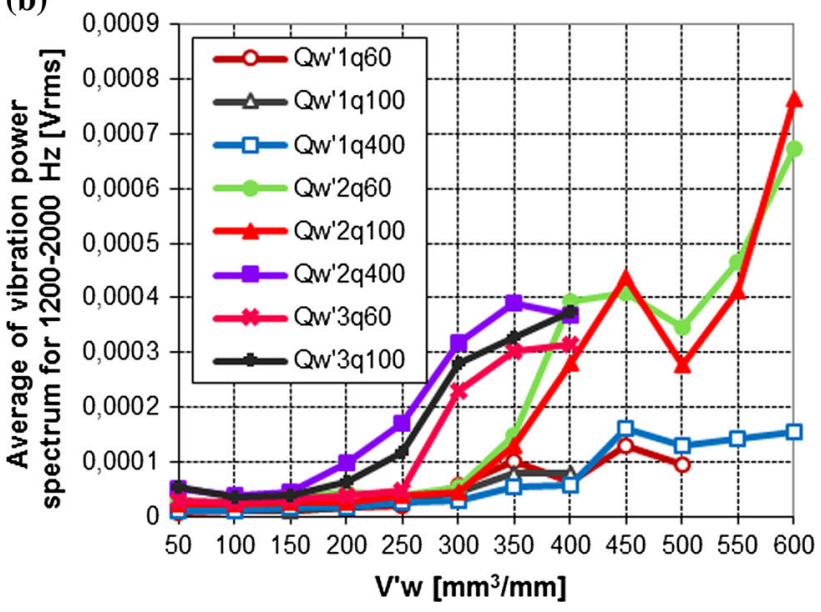

Fig. 7 Power spectrum average value of vibration signals in the frequency range of $600-1000 \mathrm{~Hz}$ (a) and $1200-2000 \mathrm{~Hz}$ (b) as a function of the specific material removal 

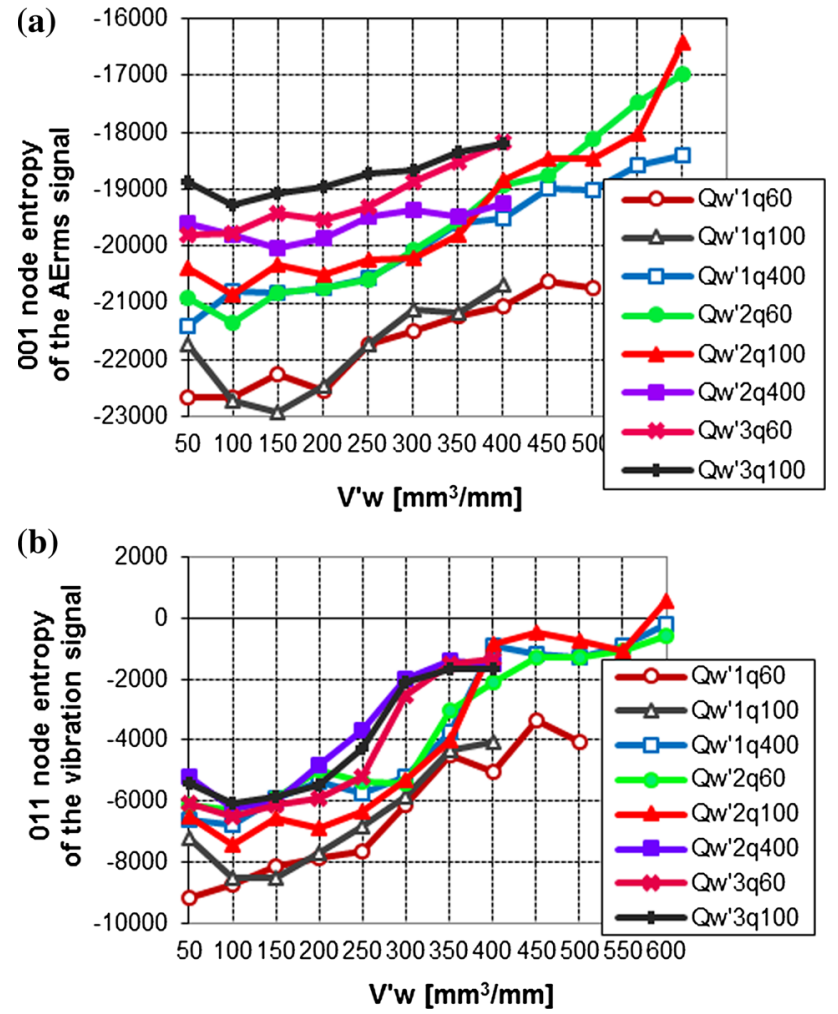

Fig. 8 Change of the wavelet coefficient entropy of the: a $A E_{R M S}$ signal in the frequency range of $600-1250 \mathrm{~Hz}$ (node 001) and $\mathbf{b}$ vibration signal in the frequency range of $1875-2500 \mathrm{~Hz}$ (node 011 ) as a function of the specific material removal

of natural frequencies of the work-piece and the grinding wheel headstock unit and they are related to the chatter because the chatter develops around the natural frequencies of the mechanical system (Inasaki et al. 2001). The results confirmed a strong correlation between the development of vibration and the wheel macro-geometry state. Vibration monitoring should include all the natural frequencies of the mechanical system.

A nonlinearity and nonstationarity of the signal has a larger significance in the case of the acoustic emission signal. This results from the features of the phenomena being the source of this signal. Because of this, a wavelet transform was used for analysis of the RMS value of AE signal and, to compare the results, also for the vibration signal analysis. The packet wavelet analysis (PWA) on the $3^{\text {rd }}$ scale level with the aid of the Symlet 8 wavelet was used for the analysis of both the signals. The parameters of the PWA were determined experimentally. The entropy of a given wavelet decomposition, expressed as $\sum \log \left(w_{i}\right)^{2}$, where $w_{i}$ - wavelet coefficients, was adopted as a measure of the energy of decomposition. The results of this analysis are presented in Fig. 8.

The obtained results indicate that the supervision of the wheel macro-geometry can also be performed with the aid of wavelet packet analysis. However in the case of vibration signal, a detailed analysis of the DFT and the PWA application shows that the impact of the removed material volume and input grinding parameters on the DFT coefficients is to some extent different than impact of the same quantities on the PWA entropy coefficients. Thus, it would be more desirable to make a decision on the wheel micro-geometry by taking into consideration all the discussed measures.

The changes of the normal and tangential forces, their ratio and the grinding wheel cutting ability coefficient $K_{z}$ were adopted as measures of the wheel micro-geometry state. The coefficient $K_{z}$ is defined as the relationship between material removal rate and normal force. The dependence of the chosen process features on specific material removal appeared to some extent to be ambiguous thus the features related to grinding force can be useful in the grinding wheel microgeometry supervision but in connection with other types of process state symptoms. The use of the raw AE signal for the grinding wheel micro-geometry supervision can be summarized as follows:

- The raw AE signal is correlated with the wheel microgeometry parameters.

- Changes occurring in grain distribution on the WCS can be revealed with the aid of the AE signal kurtosis coefficient.

- The DFT analysis of the AE signal does not give satisfactory results because of the nonlinearity and nonstationarity of the AE signal. Wavelet analysis is more suitable for this.

- The effectiveness of the kurtosis coefficient application can be increased by a determination of its value for the AE signal wavelet decomposition in frequency ranges for which the signal presents the highest power.

- The kurtosis of the AE signal is not a good measure of the grinding wheel wear in the case of the work-piece thermal damage appearance.

Different statistical measures of the AE signal were also experimentally verified for an assessment of work-piece surface roughness. The arithmetic mean, range and coefficient of the variation of this signal RMS value were adopted as signal features. An analysis of their changes during the wheel life period and the lack of their clear correlation with the work-piece roughness indicate a poor usefulness for these features for reliable roughness supervision. However, as in the case of the wheel micro-geometry, they can be useful as input components for roughness model building because of interdependences existing between different process signals.

It is proved in the case of work-pieces made of steels that the index $B_{p}$ is a good measure of the state of burns and other thermal damages on the work-piece surface after 


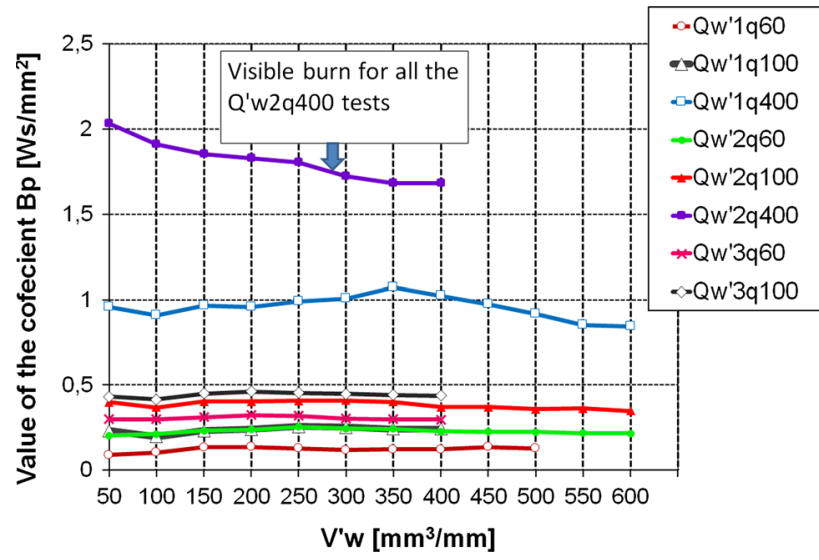

Fig. 9 The $B_{p}$ coefficient as a function of the specific material removal

grinding (Kruszyński and Wojcik 2001). It is a product of the specific grinding power and the duration of the wheel contact with a point on the work-piece surface during one work-piece revolution. In practice, a limit value of the $B_{p}$ can be determined as a constant for a given combination of grinding input conditions. The obtained values of the $\mathrm{B}_{p}$ coefficient are presented in Fig. 9.

The noticeably higher values of the $B_{p}$ can be observed for the $Q_{w}^{\prime} 3 q 60$ and $Q_{w}^{\prime} 2 q 400$ tests. During the $Q_{w}^{\prime} 3 q 60$ tests, the $B_{p}$ coefficient was about its limit value for this type of grinding so no burn is observed. During the $Q_{w}^{\prime} 2 q 400$ tests, the effect of the high value of $q$ was augmented by the higher value of the grinding force (because of the higher depth of cut $\mathrm{a}_{\mathrm{e}}$ ) what results in burn appearance.

The acoustic emission measurement is also used for thermal damage detection. It is based on the finding that an $\mathrm{AE}$ signal is generated by phenomena related to work-piece and wheel material structure deformation and to friction at the contact area.

\section{Decision table}

The data obtained during grinding tests was used to develop the decision table. Based on the analysis presented above, each grinding case was evaluated with the aid of the 17 grinding process features which made up the condition attributes set $C$. Elements of this set are described in the Table 1 .

The decision attributes set $D$ consists of five quantities belonging to important process results. They are listed in the Table 2.

For each of the decision attributes, the decision classes were established representing different states of the process. The established classes are presented in Table 3.

Assignment of the process results to a class was done according to the findings of the previous subsection.
Table 1 The condition attributes

\begin{tabular}{ll}
\hline Attribute & Attribute description \\
\hline$C_{1}$ & Specific material removal rate $Q_{w}^{\prime}$ \\
$C_{2}$ & Speed ratio $q$ \\
$C_{3}$ & Specific material removal $V_{w}^{\prime}$ \\
$C_{4}$ & Normal force $F_{n}$ \\
$C_{5}$ & Tangential force $F_{t}$ \\
$C_{6}$ & Tangential to normal force ratio $\mu$ \\
$C_{7}$ & Index of heat flux density entering the work-piece $B_{p}$ \\
$C_{8}$ & Wheel cutting ability coefficient $K_{z}$ \\
$C_{9}$ & EA signal kurtosis \\
$C_{10}$ & Kurtosis of the AE signal wavelet components in the \\
& range of $125-187.5 \mathrm{kHz}$ \\
$C_{11}$ & Vibration signal average power spectrum in the \\
$C_{12}$ & range of $600-1000 \mathrm{~Hz}$ \\
$C_{13}$ & Vibration signal average power spectrum in the \\
$C_{14}$ & range $1200-2000 \mathrm{~Hz}$ \\
$C_{15}$ & Entropy of the vibration signal wavelet components \\
$C_{16}$ & in the range of $1875-2500 \mathrm{~Hz}$ \\
$C_{17}$ & the range of $625-1250 \mathrm{~Hz}$ \\
\hline & Average value of EA
\end{tabular}

Table 2 The decision attributes

\begin{tabular}{ll}
\hline Attribute & Attribute description \\
\hline$D_{1}$ & Type of the WCS wear \\
$D_{2}$ & State of the WCS macro-geometry \\
$D_{3}$ & State of the WCS micro-geometry \\
$D_{4}$ & State of burnings and other thermal damages \\
$D_{5}$ & Roughness of the work-piece according to the $R_{a}$ \\
& parameter \\
\hline
\end{tabular}

The state of the WCS macro-geometry was assigned to a class according to the measurements of the wheel waviness. Because the parameters of the WCS bearing ratio curve describe the statistical distribution of cutting grains on the WCS two of them were used as measures of the wheel wear. The wheel wear type was assigned to a class according to changes in the reduced profile height $R_{G e s}$ and the reduced peak height $R_{p k}$ was used to determine the WCS microgeometry state. The state of burns and other thermal damages of the work-piece surface were assigned to a class according to the value of the $B_{p}$ coefficient. The assignment of the work-piece roughness to a class depends on the $R_{a}$ parameter measurements.

The principles of process results assignment to the individual decision classes are presented in Table 4. 
Table 3 The decision classes for each decision attribute (DA)

\begin{tabular}{|c|c|c|}
\hline DA & Classes & Class description \\
\hline$D_{1}$ & $\{\mathrm{~T}, \mathrm{~S}\}$ & $\begin{array}{l}\mathrm{T}=\text { Dominance of grain flat wear on WCS } \\
\mathrm{S}=\text { Dominance of grain breakage and pullout } \\
\text { on WCS }\end{array}$ \\
\hline$D_{2}$ & $\{1,2\}$ & $\begin{array}{l}1=\text { Acceptable state of WCS } \\
\text { macro-geometry, } \\
2=\text { Unacceptable state of WCS } \\
\text { macro-geometry }\end{array}$ \\
\hline$D_{3}$ & $\{1,2\}$ & $\begin{array}{l}1=\text { Fine state of WCS micro-geometry, } \\
2=\text { Unsatisfactory state of WCS } \\
\text { micro-geometry }\end{array}$ \\
\hline$D_{4}$ & $\{1,2,3\}$ & $\begin{array}{l}1=\text { No burn on work surface } \\
2=\text { Risk of burn on work surface, } \\
3=\text { Appearance of burn on work surface, }\end{array}$ \\
\hline$D_{5}$ & $\{1,2,3\}$ & $1=$ Low $R_{a}, 2=$ middle $R_{a}, 3=$ high $R_{a}$ \\
\hline
\end{tabular}

Table 4 The principles of process result assignments to the decision classes

\begin{tabular}{ll}
\hline Attribute & Principles \\
\hline$D_{1}$ & $\mathbf{T}$ if $R_{G e s}$ increases $\leq 10 \%$ for the removal of next \\
& $100 \mathrm{~mm}^{3} / \mathrm{mm}$, \\
& $\mathbf{S}$ if $R_{G e s}$ increases $>10 \%$ for the removal of next \\
& $100 \mathrm{~mm}^{3} / \mathrm{mm}$, \\
& $\mathbf{1}$ if $\mathrm{WCS}$ average amplitude in range of $10-50$ \\
& waves/WSC circumference $<0.025 \mathrm{~V}_{\mathrm{rms}}$, \\
$D_{2}$ & $\mathbf{2}$ if WCS average amplitude in range of $10-50$ \\
& $\quad$ waves $/ \mathrm{WSC}$ circumference $\geq 0.025 \mathrm{~V}_{\text {rms }}$ \\
& $\mathbf{1}$ if $R_{p k}>R_{p k}$ after dressing or after the removal of \\
& next $100 \mathrm{~mm}^{3} / \mathrm{mm}$, \\
$D_{3}$ & $\mathbf{2}$ if $R_{p k} \leq R_{p k}$ after dressing or after the removal of \\
& next $100 \mathrm{~mm}^{3} / \mathrm{mm}$ \\
& $\mathbf{1}$ if $B_{p} \leq 0.8 ; \mathbf{2}$ if $0.8<B_{p} \leq 1.6 ; \mathbf{3}$ if $B_{p}>1.6$ \\
$D_{4}$ & $\mathbf{1}$ if $R_{a} \leq 0.83 \mu \mathrm{m}, \mathbf{2}$ if $0.83<R_{a} \leq 1.25 \mu \mathrm{m}, \mathbf{3}$ if \\
$D_{5}$ & $R_{a}>1.25 \mu \mathrm{m}$
\end{tabular}

Using the procedures described above the decision table was prepared. The table consists of 78 objects which are grinding process cases diversified with respect to the specific material removal rate $Q_{w}^{\prime}$, the speed ratio $q$ and the wheel cutting ability represented by the specific material removal $V_{w}^{\prime \prime}$ since the last wheel dressing. Each object embodies a single case of grinding process working cycle characterized by the 17 condition attributes and the 5 decision attributes.

In this study, the quality of classification was equal to 1 for each of the all five decision attributes what means that the decision table did not contain inconsistent or ambiguous objects. However some condition attributes in the decision table can be redundant. Hence the quality of classification is a base for the determination of decision table reducts.

\section{Transformation of attributes into criteria-modeling of semantic correlations between attributes}

In the DRSA, continuous attributes do not require discretization. However they have to be criteria i.e. attributes with an increasing (gain type) or a decreasing (cost type) preference. For example the normal grinding force is an attribute with a decreasing preference for the WCS micro-geometry evaluation (the greater the $F_{n}$, the worse the micro-geometry state). Hence, at the stage of data preparation, the preference orders of condition and decision attributes have to be determined according to available domain knowledge.

If a condition attribute is non-ordered in its whole domain or its preference scale is unknown, it is possible to transform an attribute into a criterion (Blaszczynski et al. 2010; Greco et al. 2002). The transformation does not introduce inconsistency with respect to the dominance and allow discovering local (existing in some intervals of attribute domain) correlations between condition and decision attributes (Blaszczynski et al. 2012). The transformation of each non-ordinal condition attribute is made individually. This consists of the doubling of the attribute and assigning the increasing preference to the original and the decreasing preference to the doubled attribute.

Formally, within the transformation of numerical attributes, the original data table $S$, including set of objects $U$ described by set of attributes $V$, is transformed into data table $S^{\prime}$ including set of objects $U$ described by set of attributes $V$ ', where $\left|V^{\prime}\right|>|V|$. Each non-ordered numerical attribute in a decision table is doubled (cloned) following some principles. Each (originally non-ordered) attribute $q_{i}$ from $S$ is represented in $S^{\prime}$ as a pair of ordinal attributes (criteria) $q_{i}^{\prime}$, and $q_{i}^{\prime \prime}$. The values of $q_{i}^{\prime}$ and $q_{i}^{\prime \prime}$ are equal to $q_{i}$ for all objects from $U$. The first attribute in the pair $-q_{i}^{\prime}-$ is set to have an increasing (positive, gain type) relationship with decision attribute, while the second one $-q_{i}^{\prime \prime}-$ is set to have decreasing (negative, cost type) relationship with decision attribute.

Because of the high level of complication of relationships between process variables and process results in grinding the preferences for most condition attributes (especially for $D_{1}, D_{3}$ and $D_{4}$ ) were assumed to be unknown. In detail for the condition attributes it was assumed as follows:

- For $D_{1}$ : unknown for the all condition attributes,

- For $D_{2}$ : unknown for $C_{1}, C_{2}, C_{3}, C_{6}, C_{7}, C_{8}, C_{15}, C_{16}$, $C_{17}$; cost for $C_{4}, C_{5}, C_{9}$ to $C_{14}$.

- For $D_{3}$ : unknown for $C_{1}-C_{4}$ and $C_{11}-C_{17}$; cost for $C_{5}, C_{6}, C_{7}, C_{9}, C_{10}$; gain for $C_{8}$.

- For $D_{4}$ : unknown for the all $C$ except $C_{5}, C_{6}, C_{7}$ which were assumed to be the cost type.

- For $D_{5}$ : unknown for $C_{1}-C_{6}$ and $C_{8}$; cost for $C_{7}$ and $C_{9}-C_{14}$; gain for $C_{15}-C_{17}$. 
The preferences for all decision attributes, except the type of wheel wear (unknown preference), were assumed to be of the cost type.

\section{Data analysis and knowledge extraction}

\section{Iterative process of attributes selection}

The sets of minimal decision rules for all the decision criteria can be induced with the use of the full set of condition attributes being in the decision table or only with so-called reducts which are subsets of these full sets, determined for individual decision attributes. In the presented study, the process of condition attributes selection was strictly integrated with a model construction process i.e. it was embedded in the process of a knowledge extraction and its evaluation. For each decision attribute that procedure was conducted using an iterative approach in order to get a classifier with the best prediction performance and to minimize the risk of a false decision on process state classification. Such a general criterion takes into consideration the quality of influence of the applied classification algorithm and interrelationships occurring among the condition attributes. The iterative approach for the reduction of attribute numbers was based on the concept of reducts extended by elements of the "wrapper approach" for data selection (Baraldi et al. 2011; Kohavi and John 1997) and additionally supervised by a domain expert whose participation was helpful to orientate the knowledge discovery process. Approximation sets were computed for each of iterations. The general idea of the applied condition attribute selection process is shown in Fig. 10.

The first iteration of the analysis and induction of rules was conducted using the set of all condition attributes called initial set of attributes (Table 1). This iteration is represented in Fig. 10 by a set of steps to the first decision block. If the classification capability of the induced set of rules was unsatisfied then the second iteration of knowledge extraction and evaluation was needed. It was conducted using the subset of the initial set of attributes, distinguished by a process expert and called expert subset of attributes (ESA). If the classification capability of the rules induced from the ESA was still unsatisfied then induction of rules was continued by using reducts of the ESA or supersets of those reducts. The procedure was repeated until the best possible prediction performance was achieved. This is illustrated in Fig. 2 by the feedback between the attributes selection block and the decision making on the obtained set of rules acceptance.

The choice of a reduct or building of its superset as the set of attributes valid in the next iteration of an analysis was based on results of previous iterations and expert knowledge. The procedure was repeated from several to ten times until the possibly best prediction capability was achieved for each

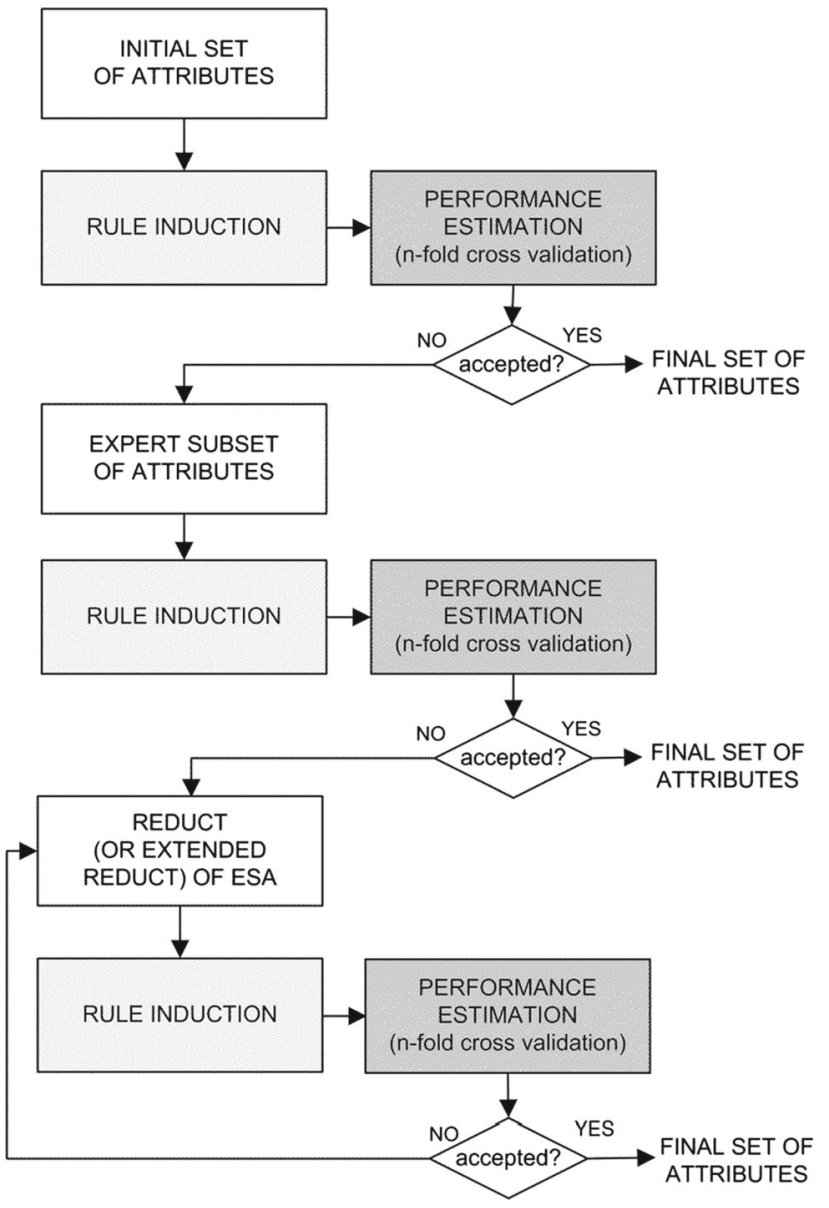

Fig. 10 Idea of the condition attribute selection process

diagnostics subsystem (i.e. each process result) separately. The condition attributes taken into consideration in the last iteration (finished with $Y E S$ answer in the last decision block in Fig. 10) have become the outcome of the attributes selection process and called the final set of attributes.

It is worth mentioning that reducts defined within the rough sets theory are being specified in the literature as a feature selection method (Cios et al. 2007; Ciupke 2005). The use of a reduct guarantees the right classification of a given data set, however it is insufficient with respect to the prediction quality (Ciupke 2005). As mentioned above, an evaluation of the classification capability of the induced rules was carried out after each iteration of the condition attribute selection and rule induction process. The leave-oneout method was used for this purpose. This is a variation of the $n$ fold cross validation test used for data sets with the number of objects smaller than 100. Based on this method the predictive performance of the induced models was estimated using different measures commonly used in the DRSA. These measures are discussed in the section on model evaluation and discussion. 


\section{Induction of rules}

The DRSA classifies objects into some number of separated decision classes but these classes are ordered in such a way that the higher the class number the better the class according to their preference. Thus, the idea of a single class is replaced by the idea of a union of classes. So the decision rules in the DRSA are induced from lower and upper approximations of upward or downward unions of classes representing ordered sets of decision classes (the union of classes of "at least good" includes the classes "good" and "excellent" whereas the union of "at most good" includes the classes "good" and "pure"). Additionally, the condition parts of rules generated from continuous attributes are constructed by means of relations " $\geq$ ", " $\leq$ " and "=" instead of only "=", which enables a more compact knowledge representation and does not require the discretization of quantitative attributes.

The induction of rules was conducted using the VCDomLEM algorithm (Blaszczynski et al. 2011). The induced sets of rules constitute a rule model for the external cylindrical plunge grinding process. The final models for the five process outputs are presented in Tables 5, 6, 7, 8 and 9.

\section{Model evaluation and discussion}

The evaluation of the classification capability of the induced rules was carried out using a set of measures.

Table 5 The rule model of the type of WCS wear

\begin{tabular}{lll}
\hline No. & Conditions & Decision \\
\hline 1 & $\left(C_{1}=2\right)$ & At least $\mathrm{S}$ \\
2 & $\left(C_{1}=3\right)$ & At least $\mathrm{S}$ \\
3 & $\left(C_{2}=400\right) \&\left(\mathrm{C}_{3} \geq 350\right)$ & At least $\mathrm{S}$ \\
4 & $\left(C_{1}=1\right) \&\left(\mathrm{C}_{3} \leq 300\right)$ & At most $\mathrm{T}$ \\
5 & $\left(C_{1}=1\right) \&\left(\mathrm{C}_{2}=60\right)$ & At most $\mathrm{T}$ \\
6 & $\left(C_{1}=1\right) \&\left(\mathrm{C}_{2}=100\right)$ & At most $\mathrm{T}$
\end{tabular}

Table 6 The rule model of the wheel macro-geometry state

\begin{tabular}{lll}
\hline No. & Conditions & Decision \\
\hline 1 & $\left(\mathrm{C}_{11} \leq 0.000052003\right) \&\left(\mathrm{C}_{12} \leq 0.000057067\right)$ & At least 1 \\
2 & $\left(\mathrm{C}_{11} \leq 0.00006174\right) \&\left(\mathrm{C}_{17} \leq 7.29041\right)$ & At least 1 \\
3 & $\left(\mathrm{C}_{2}=400\right) \&\left(\mathrm{C}_{13} \leq-3709.354539\right)$ & At least 1 \\
4 & $\left(\mathrm{C}_{1}=2\right) \&\left(\mathrm{C}_{2}=100\right) \&\left(\mathrm{C}_{11} \leq\right.$ & At least 1 \\
& $0.000212465) \&\left(\mathrm{C}_{12} \leq 0.000278944\right)$ & \\
5 & $\left(\mathrm{C}_{12} \geq 0.000281637\right)$ & At most 2 \\
6 & $\left(\mathrm{C}_{11} \geq 0.000219779\right)$ & At most 2 \\
7 & $\left(\mathrm{C}_{1}=3\right) \&\left(\mathrm{C}_{11} \geq 0.000123433\right)$ & At most 2 \\
8 & $\left(\mathrm{C}_{2}=60\right) \&\left(\mathrm{C}_{11} \geq 0.000083852\right)$ & At most 2 \\
9 & $\left(\mathrm{C}_{12} \geq 0.000063081\right) \&\left(\mathrm{C}_{17} \geq 7.67326\right)$ & At most 2 \\
\hline
\end{tabular}

Table 7 The rule model of the wheel micro-geometry state

\begin{tabular}{lll}
\hline No. & Conditions & Decision \\
\hline 1 & $\left(\mathrm{C}_{6} \leq 0.377\right)$ & At least 1 \\
2 & $\left(\mathrm{C}_{2}=60\right) \&\left(\mathrm{C}_{3} \leq 250\right)$ & At least 1 \\
3 & $\left(\mathrm{C}_{1}=3\right) \&\left(\mathrm{C}_{2}=60\right)$ & At least 1 \\
4 & $\left(\mathrm{C}_{3} \geq 350\right) \&\left(\mathrm{C}_{6} \leq 0.459\right)$ & At least 1 \\
5 & $\left(\mathrm{C}_{1}=2\right) \&\left(\mathrm{C}_{6} \leq 0.449\right)$ & At least 1 \\
6 & $\left(\mathrm{C}_{3} \leq 100\right) \&\left(\mathrm{C}_{6} \leq 0.465\right)$ & At least 1 \\
7 & $\left(\mathrm{C}_{1}=2\right) \&\left(\mathrm{C}_{2}=100\right) \&\left(\mathrm{C}_{6} \leq 0.521\right)$ & At least 1 \\
8 & $\left(\mathrm{C}_{1}=1\right) \&\left(\mathrm{C}_{2}=400\right) \&\left(\mathrm{C}_{3} \geq 150\right)$ & At least 1 \\
9 & $\left(\mathrm{C}_{3} \leq 100\right) \&\left(\mathrm{C}_{6} \geq 0.522\right)$ & At most 2 \\
10 & $\left(\mathrm{C}_{1}=1\right) \&\left(\mathrm{C}_{2}=100\right) \&\left(\mathrm{C}_{6} \geq 0.487\right)$ & At most 2 \\
11 & $\left(\mathrm{C}_{1}=2\right) \&\left(\mathrm{C}_{2}=400\right) \&\left(\mathrm{C}_{3} \geq 150\right) \&\left(\mathrm{C}_{6} \geq 0.456\right)$ & At most 2 \\
12 & $\left(\mathrm{C}_{1}=3\right) \&\left(\mathrm{C}_{2}=100\right) \&\left(\mathrm{C}_{3} \geq 150\right) \&\left(\mathrm{C}_{3} \leq 200\right)$ & At most 2 \\
13 & $\left(\mathrm{C}_{2}=60\right) \&\left(\mathrm{C}_{3} \geq 300\right) \&\left(\mathrm{C}_{6} \geq 0.458\right)$ & At most 2 \\
14 & $\left(\mathrm{C}_{1}=1\right) \&\left(\mathrm{C}_{2}=60\right) \&\left(\mathrm{C}_{3} \leq 300\right) \&\left(\mathrm{C}_{3} \geq 300\right)$ & At most 2
\end{tabular}

Table 8 The rule model of the thermal damages state

\begin{tabular}{lll}
\hline No. & Conditions & Decision \\
\hline 1 & $\left(\mathrm{C}_{15} \leq 2.731\right)$ & At least 1 \\
2 & $\left(\mathrm{C}_{1}=3\right)$ & At least 1 \\
3 & $\left(\mathrm{C}_{1}=2\right) \&\left(\mathrm{C}_{15} \leq 4.055\right)$ & At least 1 \\
4 & $\left(\mathrm{C}_{1}=2\right) \&\left(\mathrm{C}_{3} \leq 250\right) \&\left(\mathrm{C}_{15} \leq 4.184\right)$ & At least 1 \\
5 & $\left(\mathrm{C}_{15} \leq 4.055\right)$ & At least 2 \\
6 & $\left(\mathrm{C}_{3} \leq 250\right) \&\left(\mathrm{C}_{15} \leq 4.184\right)$ & At least 2 \\
7 & $\left(\mathrm{C}_{1}=2\right) \&\left(\mathrm{C}_{15} \geq 4.236\right)$ & At most 3 \\
8 & $\left(\mathrm{C}_{1}=2\right) \&\left(\mathrm{C}_{3} \geq 350\right) \&\left(\mathrm{C}_{15} \geq 4.152\right)$ & At most 3 \\
9 & $\left(\mathrm{C}_{1}=1\right) \&\left(\mathrm{C}_{15} \geq 2.930\right)$ & At most 2
\end{tabular}

Table 9 The rule model of the work-piece roughness

\begin{tabular}{lll}
\hline No. & Conditions & Decision \\
\hline 1 & $\left(\mathrm{C}_{1}=1\right) \&\left(\mathrm{C}_{3} \leq 450\right)$ & At least 1 \\
2 & $\left(\mathrm{C}_{1}=1\right) \&\left(\mathrm{C}_{2}=400\right) \&\left(\mathrm{C}_{3} \leq 500\right)$ & At least 1 \\
3 & $\left(\mathrm{C}_{2}=100\right) \&\left(\mathrm{C}_{3} \leq 200\right)$ & At least 1 \\
4 & $\left(\mathrm{C}_{3} \leq 250\right) \&\left(\mathrm{C}_{7} \leq 0.254\right)$ & At least 1 \\
5 & $\left(\mathrm{C}_{1}=1\right)$ & At least 2 \\
6 & $\left(\mathrm{C}_{7} \leq 0.254\right)$ & At least 2 \\
7 & $\left(\mathrm{C}_{2}=100\right)$ & At least 2 \\
8 & $\left(\mathrm{C}_{7} \geq 1.683\right)$ & At most 3 \\
9 & $\left(\mathrm{C}_{1}=3\right) \&\left(\mathrm{C}_{2}=60\right)$ & At most 3 \\
10 & $\left(\mathrm{C}_{3} \geq 550\right)$ & At most 2 \\
11 & $\left(\mathrm{C}_{2}=60\right) \&\left(\mathrm{C}_{3} \geq 500\right)$ & At most 2 \\
12 & $\left(\mathrm{C}_{1}=3\right) \&\left(\mathrm{C}_{3} \geq 250\right)$ & At most 2 \\
13 & $\left(\mathrm{C}_{1}=2\right) \&\left(\mathrm{C}_{3} \geq 300\right)$ & At most 2 \\
14 & $\left(\mathrm{C}_{1}=2\right) \&\left(\mathrm{C}_{7} \geq 0.407\right)$ & At most 2 \\
\hline
\end{tabular}




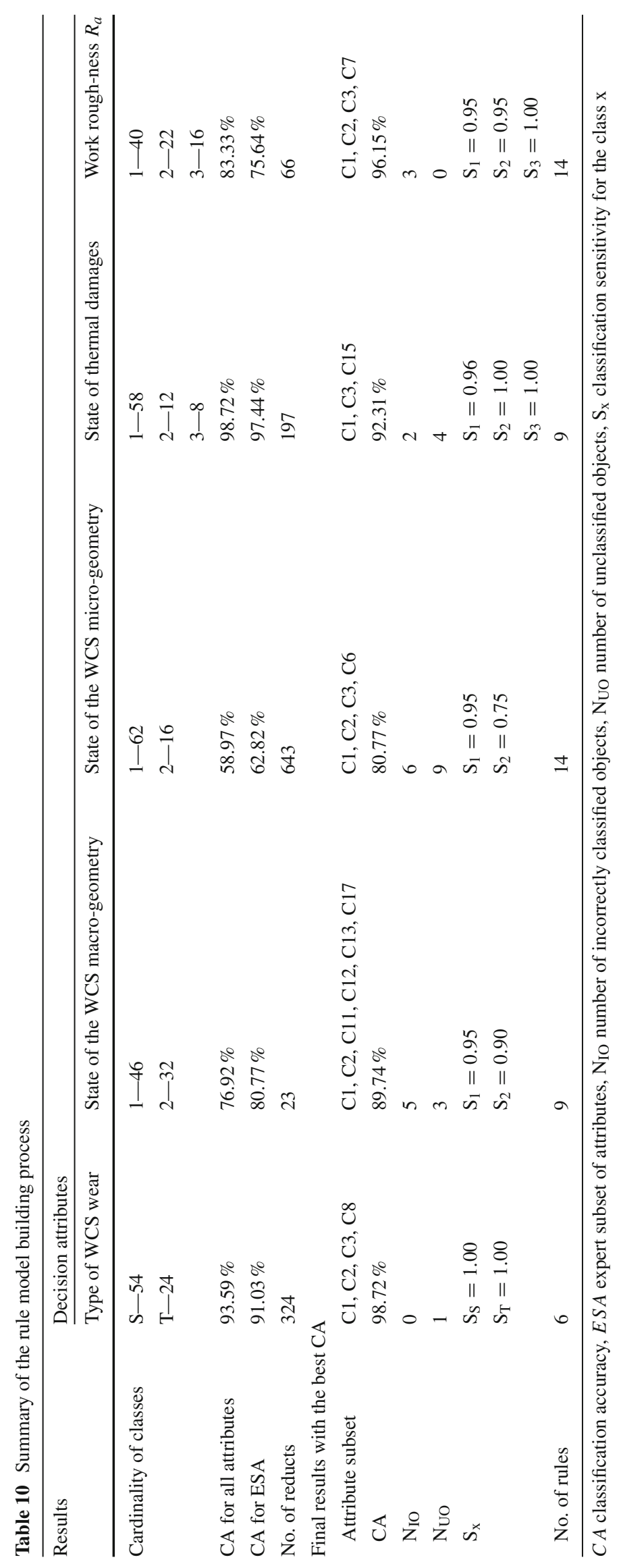


The most popular measure of this type is the classification accuracy $C A$. It is defined as a ratio of the correctly classified test objects to all the test objects. The more sophisticated analysis of incorrectly classified objects is possible thanks to use of a misclassification matrix (a confusion matrix) which is the $k \times k$ matrix, where $k$ is the number of decision classes. Each column of the matrix represents the decisions estimated by a classifier (predicted assignments), while each row represents the original decisions (original assignments).

Based on the confusion matrix, additional measures of classification capability can be calculated (separately for each of decision classes). Among them, the number of incorrectly classified objects $N_{I O}$ and the number of unclassified objects $N_{U} O$ are informative measures. From among numerous methods for correction of an imbalance in datasets for fault diagnosis (Santos et al. 2015) we decided to use a measure which is especially appropriate for a classifier's performance evaluation in situations with a great class imbalance is the sensitivity $S_{x}$. If the $T P_{x}$ (true positive) means the number of correctly classified objects from the class $x$ and the $F N_{x}$ (false negative) means the number of wrongly classified objects from the class $x$ then the sensitivity $S_{x}$ is defined as follows (Cios et al. 2007):

$S_{x}=\frac{T P_{x}}{T P_{x}+F N_{x}}$

Table 10 summarizes the course of model building process and gives the final model predictive performance estimated with the aid all of the measures defined above. All computations were completed with the aid of the jMAF software (jMAF 2011).

The obtained classification accuracy for the type of the WCS wear and the work roughness can be assessed as very good while the classification accuracy of the state of the WCS macro-geometry as good. The method of the WCS macrogeometry state assignment to a class was probably a reason of the lower value of the last CA.

The state of thermal damages was assigned to one of its three classes based on the value of the $B_{p}$ coefficient. Thus this coefficient could not be used as one of the condition attributes in the thermal state assessment. The sensitivity calculated for minority classes (class 2 and 3) was maximal (1) and for the majority class 1 it was almost maximal (0.96). However among unclassified cases there were three which belong originally to the class 3 and one belonging to the class 1 . It means that $37.5 \%$ (3/8) of all cases representing an appearance of burn on the work surface remained without classification decision. Although the CA of the thermal damages exceeds $90 \%$, the lack of burn detection in three cases makes this classification doubtful for the sake of high importance of the burn in grinding process result assessment. On the other hand, the unclassified cases as a classifier's answer can be interpreted as a warning signal meaning the appear- ance of burn with the probability equal to 0.75 (3/4). It was confirmed that the $B_{p}$ value is a reliable and simple index of grinding thermal damages. Unfortunately it requires the tangential force to be measured what requires a quite complex sensor to be used.

The lowest CA was obtained for state of the WCS microgeometry. A significant class imbalance in this case was probably a reason for such a classification result. The ratio of cardinality of objects in classes 1 and 2 was about 4 to 1. Sensitivity of class 2 was equal to 0.75 (only $9 / 12$ correct recognitions), while for the class 1 it was equal to 0.95 . Furthermore, the number of unclassified cases from class 2 was relatively large ( $4 / 16$ cases). It means that $25 \%$ of the all cases representing unacceptable state was left without classification decision and among $75 \%$ of the all classified cases the next $75 \%$ was correctly classified (resulting in about only $56 \%$ recognizability of the unacceptable state). In practice, a lack of classification of the WCS micro-geometry to one of the classes is more preferable than incorrect classification because this criterion is not so much crucial from the point of view of other grinding process results. Thus, the unsatisfactory state of WCS micro-geometry should be treated as a kind of warning and not as an indication that the wheel life is absolutely finished.

For the all investigated decision criteria, a decision about the process state should be made taking into account both the process inputs $Q_{w}^{\prime}$ and $q$ as well as the current value of $V_{w}^{\prime}$. Furthermore, the dependence of: the WCS macrogeometry on vibration features, the WCS micro-geometry on the force components, the thermal damages on the value of $B_{p}$ coefficient and the work-piece roughness on the values of $A E_{R M S}$, vibration and $B_{p}$ resulting from the literature study and theoretical analysis were confirmed. But some of the features applied, e.g. all of the raw AE signal features, turned out to be less important than others used in this study for the grinding process diagnosis.

\section{Conclusions}

The induced rule model of the process can be used as a knowledge base of an expert system for the external cylindrical plunge grinding process state evaluation and diagnosis. The DRSA automatically generates knowledge about the process from examples gathered in the decision table - one of the most difficult problems in expert system building. Using the DRSA, five minimal sets of decision rules were generated. They allow all the example grinding cases to be classified according to the original classes determined for the 5 different criteria of the process evaluation and they can be used for the classification of new process cases.

Like all artificial intelligence techniques, the DRSA requires special attention to be devoted to some elements of 
its procedure. Primarily, the proper assignment of the objects in a decision table to a decision class is important. The next crucial step is the determination of the preference directions of attributes. This has a great influence on the permissible condition parts of rules to be induced. Although the doubling of attributes is a solution for a misleading preference determination it results in a growing number of attributes which makes the analysis, especially the process of attribute selection, more difficult and time consuming.

The attributes selection was an important issue in the presented study because of relatively great number of them in the initial decision table resulting in an unfavorable ratio of attributes number (17) to number of cases in the analyzed data set (78). The applied prediction oriented, iterative approach to the reduction of attributes number appeared to be effective. It was generally based on the concept of reducts, but also extended by elements of a wrapper approach for data selection and moreover supervised by a domain expert whose participation in the feature selection process is helpful to orientate the knowledge discovery process. However the participation of an expert can be an obstacle to the full automation of the feature selection. All of this points to the direction of further research on the DRSA application.

Acknowledgements The research has been partially supported by the Polish Ministry of Science and Higher Education, Grant No. N503 198837.

Open Access This article is distributed under the terms of the Creative Commons Attribution 4.0 International License (http://creativecomm ons.org/licenses/by/4.0/), which permits unrestricted use, distribution, and reproduction in any medium, provided you give appropriate credit to the original author(s) and the source, provide a link to the Creative Commons license, and indicate if changes were made.

\section{References}

Baraldi, P., Canesi, R., Zio, E., Seraoui, R., \& Chevalier, R. (2011). Genetic algorithm-based wrapper approach for grouping condition monitoring signals of nuclear power plant components. Integrated Computer-Aided Engineering, 18, 221-234.

Blaszczynski, J., Greco, S., \& Slowinski, R. (2010). Ordinal and non-ordinal classification using monotonic rules. In Proceedings of 8th international conference of modeling and simulationMOSIM'10, Hammamet-Tunisia (pp. 1176-1184).

Blaszczynski, J., Greco, S., \& Slowinski, R. (2007). Multi-criteria classification-A new scheme for application of dominance-based decision rules. European Journal of Operational Research, 181(3), 1030-1044.

Blaszczynski, J., Greco, S., \& Slowinski, R. (2012). Inductive discovery of laws using monotonic rules. Engineering Applications of Artificial Intelligence, 25(2), 284-294.

Blaszczynski, J., Slowinski, R., \& Szeląg, M. (2011). Sequential covering rule induction algorithm for variable consistency rough set approaches. Information Sciences, 181, 987-1002.

Brinksmeier, E., Aurich, J. C., Govekar, E., Heinzel, C., Hoffmeister, H.W., Klocke, F., et al. (2006). Advances in modeling and simulation of grinding processes. CIRP Annals-Manufacturing Technology, $55(2), 1-30$.
Brinksmeier, E., \& Werner, F. (1992). Monitoring of grinding wheel wear. CIRP Annals-Manufacturing Technology, 41(1), 373-376.

Cios, K. J., Pedrycz, W., Swiniarski, R. W., \& Kurgan, L. (2007). Data mining. A knowledge discovery approach. New York: Springer.

Ciupke, K. (2005). A comparative study on methods of reduction and selection of information in technical diagnostics. Mechanical Systems and Signal Processing, 19, 919-938.

Greco, S., Matarazzo, B., Slowinski, R., \& Stefanowski, J. (2000). An algorithm for induction of decision rules consistent with the dominance principle. In: W. Ziarko \& Y. Y. Yao (Eds.), Rough sets and current trends in computing. Lecture notes in computer science (Vol. 2005, pp. 304-313). Berlin: Springer.

Greco, S., Matarazzo, B., \& Slowinski, R. (2001). Rough sets theory for multi-criteria decision analysis. European Journal of Operational Research, 129, 1-47.

Greco, S., Matarazzo, B., \& Slowinski, R. (2002). Rough approximation by dominance relations. International Journal of Intelligent Systems, 17, 153-171.

Greco, S., Matarazzo, B., \& Slowinski, R. (2005). Decision rule approach. In J. Figueira, S. Greco, \& M. Ehrgott (Eds.), Multiple criteria decision analysis: State of the art surveys (Chapter 13) (pp. 507-563). Berlin: Springer.

Grzenda, M., Bustillo, A., Quintana, G., \& Ciurana, J. (2012). Improvement of surface roughness models for face milling operations through dimensionality reduction. Integrated Computer-Aided Engineering, 19, 179-197.

Inasaki, I., Karpuszewski, B., \& Lee, H.-S. (2001). Grinding chatterorigin and suppression. CIRP Annals-Manufacturing Technology, $50(2), 515-534$.

jMAF. (2011). Dominance-based rough set approach data analysis framework. Laboratory of Intelligent Decision Support Systems of the Poznan University of Technology. http://www-idss.cs.put. poznan.pl/site/139.html. Accessed 2 October 2011.

Karpuszewski, B., Wehmeier, M., \& Inasaki, I. (2000). Grinding monitoring system based on power and acoustic emission sensors. CIRP Annals-Manufacturing Technology, 49(1), 235-240.

Kohavi, R., \& John, G. H. (1997). Wrappers for feature subset selection. Artificial Intelligence, 97, 273-324.

Kruszyński, B. W., \& Wojcik, R. (2001). Residual stress in grinding. Journal of Materials Processing Technology, 109, 254-257.

Kusiak, A. (2001). Rough set theory: A data mining tool for semiconductor manufacturing. IEEE Transactions on Electronics Packaging Manufacturing, 24(1), 44-50.

Kwak, J.-S., \& Song, J.-B. (2001). Trouble diagnosis of grinding process by using acoustic emission signals. International Journal of Machine Tools and Manufacture, 41, 899-913.

Lajmert, P., \& Lezanski, P. (2013). Monitoring of external cylindrical plunge grinding process. Archives of Mechanical Technology and Automation, 33/3(2013), 3-15.

Lezanski, P. (2001). An intelligent system for grinding wheel condition monitoring. Journal of Materials Processing Technology, 109, 258-263.

Liao, T. W. (2010). Feature extraction and selection from acoustic signals with an application in grinding wheel condition monitoring. Engineering Applications of Artificial Intelligence, 23, 74-84.

Liao, T. W., Hua, G., Qu, J., \& Blau, P. J. (2006). Grinding wheel condition monitoring with hidden Markov model-based clustering methods. Machining Science and Technology: An International Journal, 10(4), 511-538.

Liao, W. T., Tang, F., Qu, J., \& Blau, P. J. (2008). Grinding wheel condition monitoring with boosted minimum distance classifiers. Mechanical Systems and Signal Processing, 22, 217-232.

Liao, T. W., Ting, C.-F., Qu, J., \& Blau, P. J. (2007). A wavelet-based methodology for grinding wheel condition monitoring. International Journal of Machine Tools and Manufacture, 47, 580-592. 
Li-Ming, X., Kai-Zhou, X., \& Yun-Dong, C. (2010). Identification of grinding wheel wear signature by a wavelet packet decomposition method. Journal of Shanghai Jiaotong University (Science), 15(3), 323-328.

Liu, Q., Chen, X., \& Gindy, N. (2005). Fuzzy pattern recognition of AE signals for grinding burn. International Journal of Machine Tools and Manufacture, 45, 811-818.

Mannar, K., \& Ceglarek, D. (2004). Continuous failure diagnosis for assembly systems using rough set approach. CIRP AnnalsManufacturing Technology, 53(1), 39-42.

Mannar, K., Ceglarek, D., Niu, F., \& Abifaraj, B. (2006). Fault region localization (FRL): Product and process improvement based on field performance and distributed manufacturing measurements. IEEE Transactions on Automation Science and Engineering, 3(4), 423-439.

Maris, M., Snoeys, R., \& Peters, J. (1975). Analysis of plunge grinding operations. CIRP Annals-Manufacturing Technology, 24(2), 225230.

Nandi, A. K., Pratihar, D. K., \& Banerjee, M. K. (2004). Prediction of grinding power and surface finish-A GA-fuzzy approach. Integrated Computer-Aided Engineering, 11, 373-382.

Pawlak, Z. (1982). Rough sets. International Journal of Information \& Computer Sciences, 11, 341-356.
Pilacinska, M., Kujawinska, A., \& Rogalewicz, M. (2011). An expert system for the manufacturing process state evaluationassumptions. In P. Jałowiecki, P. Łukasiewicz, \& A. Orłowski (Eds.), Information systems in management, business intelligence and knowledge management (pp. 66-77). Warsaw: WULS Press.

Santos, P., Maudes, J., \& Bustillo, A. (2015). Identifying maximum imbalance in datasets for fault diagnosis of gearboxes. Journal of Intelligent Manufacturing, doi:10.1007/s10845-015-1110-0.

Slowinski, R., Greco, S., \& Matarazzo, B. (2009). Rough sets in decision making. In R. A. Meyers (Ed.), Encyclopedia of complexity and systems science (pp. 7753-7786). New York: Springer.

Teti, R., Jemielniak, K., O’Donnell, G., \& Dornfeld, D. (2010). Advanced monitoring of machining operations. CIRP AnnalsManufacturing Technology, 59(2), 717-739.

Tönshoff, H. K., Friemuth, T., \& Becker, J. C. (2002). Process monitoring in grinding. CIRP Annals-Manufacturing Technology, 51(2), $551-571$.

Wang, Z., Willett, P., DeAguiar, P. R., \& Webster, J. (2001). Neural network detection of grinding burn from acoustic emission. International Journal of Machine Tools and Manufacture, 41, 283-309. 